\title{
РЫНОК ИПОТЕЧНОГО КРЕДИТОВАНИЯ РОССИИ, ПОСЛЕДСТВИЯ КОРОНАВИРУСА COVID-19
}

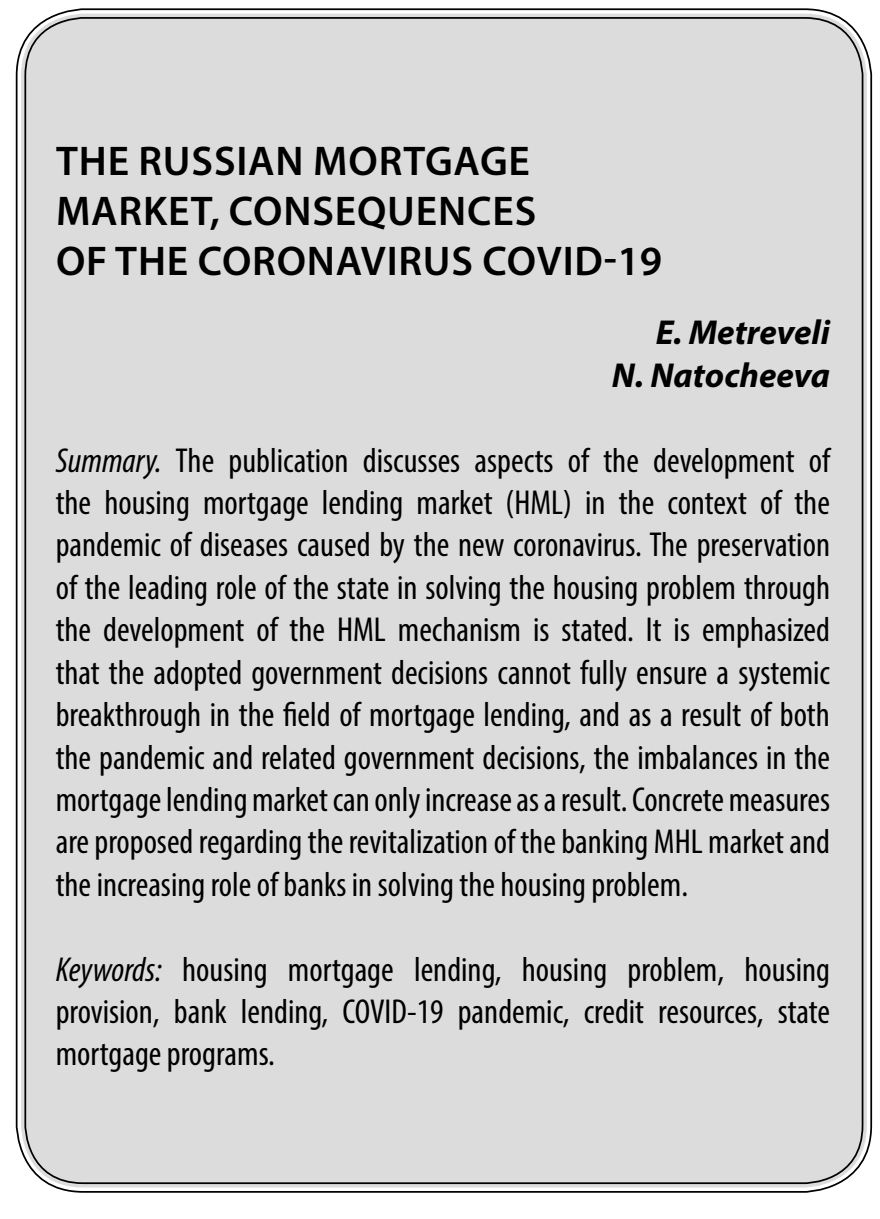

\section{Введение}

A ктуальность развития ипотечного жилищного кредитования (ИЖК) в контексте комплексного решения жилищной проблемы в Российской Федерации не подлежит сомнению. Многочисленные исследования как отечественных, так и зарубежных авторов, в частности, [1-4], подтверждают приоритетный характер ипотечного кредитного финансового механизма в решении вопроса обеспечения граждан страны доступным и комфортным жильем, сохраняющаяся невысокая доступность которого и составляет основу жилищной проблемы на современном этапе социально-экономического развития [5]. Несмотря на значительную активность субъектов публичной политики, направленную на преимущественно административное стимулирование расширенного развития рынка ИЖК, значительный прогресс в сфере ипотечного кредитования в России до настоящего времени не обеспечен: ус-

\author{
Метревели Елизавета Георгиевна \\ Аспирант, преподаватель, РЭУ им. Г.В. Плеханова \\ metrevelieg@yandex.ru \\ Наточеева Наталья Николаевна \\ Д.э.н., профессор, РЭУ им. Г.В. Плеханова
}

Аннотация. В публикации рассматриваются аспекты развития рынка ипотечного жилищного кредитования (ИЖК) в контексте пандемии заболеваний, вызванных новым коронавирусом. Констатируется сохранение руководящей роли государства в решении жилищной проблемы через развитие механизма ИЖК. Подчёркивается при этом, что принятые государственные решения не могут в полной мере обеспечить системный прорыв в сфере ипотечного кредитования, и вследствие как пандемии, так и связанных с ней государственных решений, диспропорции на рынке ипотечного кредитования могут в результате лишь усилиться. Предлагаются конкретные меры по поводу активизации рынка банковского ИЖК, повышения роли банков в решении жилищной проблемы.

Ключевые слова: ипотечное жилищное кредитование, жилищная проблема, обеспеченность жильем, банковское кредитование, пандемия COVID-19, кредитные ресурсы, государственные ипотечные программы. ловия кредитования остаются не выгодными для большинства лиц, стремящихся улучшить свои жилищные условия, а действительно привлекательные ипотечные программы единичные и доступны вовсе не каждому. Пандемия заболеваний, вызванных новым коронавируCom COVID-19 (далее - пандемия COVID-19), не только вскрыла проблемы в ипотечном кредитном механизме, но и может представлять возможности для его совершенствования, если таковыми своевременно, грамотно и полноценно воспользоваться.

\section{Материалы и метолы}

Исследование построено на основе системно-структурного подхода к изучению состояния и проблем ипотечного жилищного кредитования. Анализ статистики решения жилищного вопроса и развития ИЖК проведен по материалам Росстата, Банка России и Банка «ДОМ.РФ» с применением методов экономико-статистического анализа. 


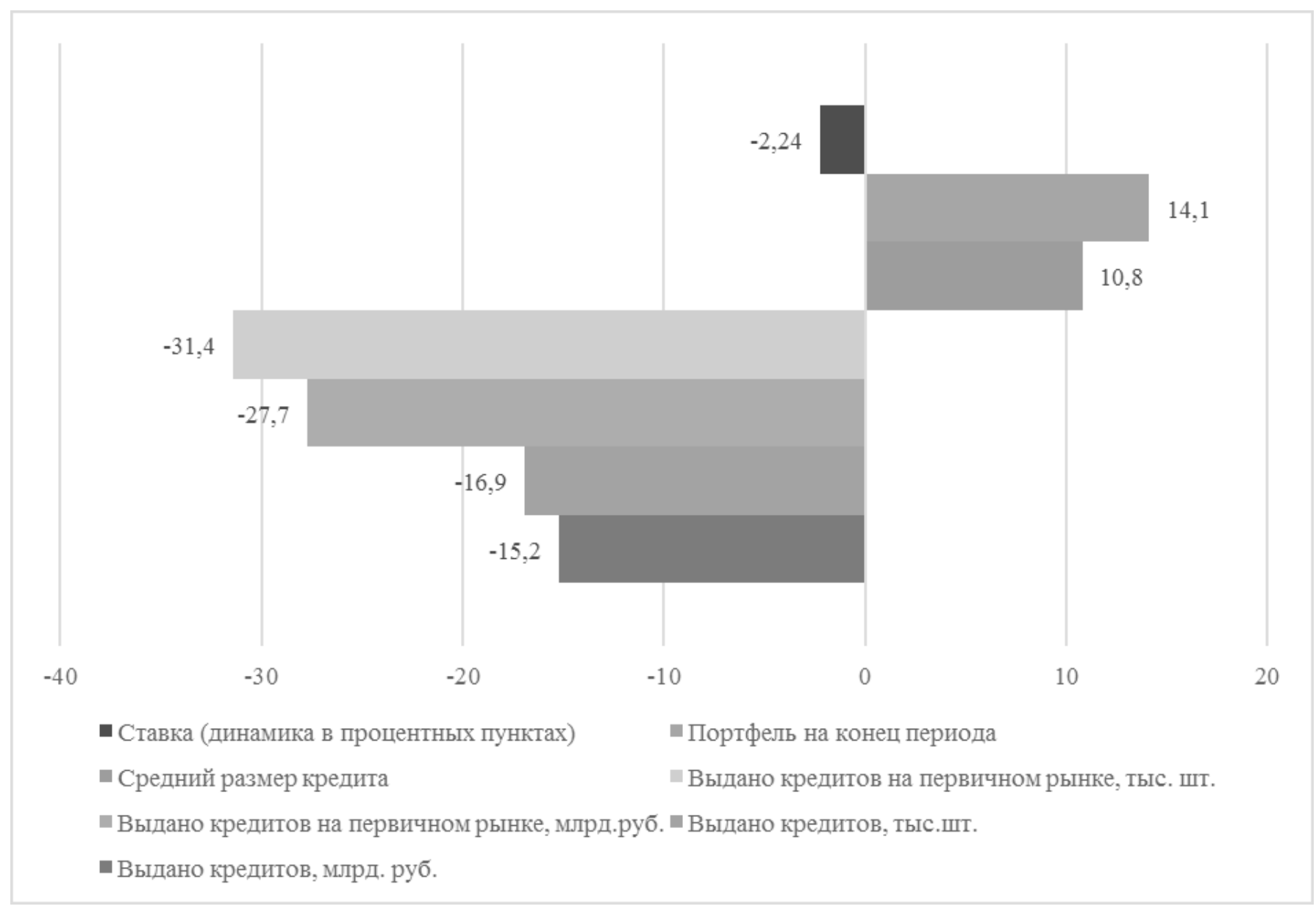

Рис. 1. Показатели функционирования российского ипотечного рынка в апреле 2020 г. в сравнении с а.п.п.г.,\% [10]

\section{Результаты и обсужление}

Жилищный вопрос остается одной из ключевых проблем в социальной сфере в современной России. Став следствием стечения многих обстоятельств, жилищная проблема остается на повестке дня социально-экономического развития еще с советских времен. На сегодняшний день отсутствуют единые объективные данные по поводу состояния жилищной проблемы: официальная статистика основывается на характеристиках жилища, спорных с позиций соответствия современным требованиям комфорта и качества жилья; опираясь на соответствующие данные, можно лишь говорить об обеспеченности жилой площадью, однако не о ее качестве. Более качественные оценки дают опросы населения, и они позволяют утверждать, что 8 из 10 россиян не довольны своими жилищными условиями, и готовы были бы их улучшить, если бы имели такую возможность [6].

Приобрести жилье в собственность многим гражданам мешает нехватка собственных средств. Жилая недви- жимость, традиционно, одна из самых дорогостоящих сфер. По этой причине, не только в России, но и за рубежом, значительное число граждан приобретает жилье в кредит [7]. Ипотечное жилищное кредитование, при этом, представляет сложный механизм: доступность кредита для граждан в полной мере зависит от низких ставок и длинных, до 20 лет и более, сроков кредитования. Однако одновременно достичь двух параметров сложно: длинные сроки мультиплицируют риски, влияя на стоимость кредита. Один из способов снизить риски - рефинансирование ипотечных кредитов, которое и выступает, через инструменты секьюритизации и выпуска ипотечных ценных бумаг, основой современного механизма ИЖК.

В механизме ИЖК важную роль играет государство, роль которого существенно возрастает в странах с дисбалансами в кредитной системе и не развитым ипотечным рынком, включая Российскую Федерацию. В нашей стране, роль государства на рынке ИЖК постоянно растет. С учетом траекторий вовлечения государства в ИЖК, активизация внимания правительства к ИЖК в условиях 
кризиса, вызванного пандемией COVID-19, не вызывает удивления, тем более что основные структурные проблемы и диспропорции на рынке ИЖК до сих пор не решены. В частности, ипотечные жилищные кредиты все еще доступны, как правило, заемщикам с достаточно высокими уровнями доходов; многие привлекательные ипотечные программы практически не реализуются региональными банками, в особенности работающими по базовой лицензии, для которых крайне затруднен доступ к дешевому и расширенному финансированию и велики затраты на обслуживание долгосрочного кредитования; рынок ИЖК «сконцентрирован» в руках ТОП-крупнейших банков, прежде всего, государственных, и структура лидеров рынка, их доля от года к году не меняется [8].

Пандемия коронавируса усложняет условия функционирования экономики. На протяжении более трех месяцев вынужденной изоляции существенно замедлилась деловая активность. Меняется и стратегия расходования средств гражданами, более ориентированными на сбережения. Многие заемщики, которые финансировали ранее взятые ИЖК, лишаются возможности своевременно исполнять обязательства по уплате процентов и возврату основного долга: значительное число работников направлено в вынужденный простой, многие лишились переменной части заработной платы, кто-то вовсе потерял работу. Говорить в таких условиях о выдаче новых кредитов вовсе не приходится, и даже те, кто ранее планировал приобрести жилье в кредит по ипотечной программе, все более склонны отложить покупку до более спокойных и прогнозируемых времен. В условиях растущих рисков, банки все более строго подходят к оценке заемщиков. Не поддерживаемый со стороны ИЖК, и в условиях общей стагнации потребительского спроса, рынок жилой недвижимости по всей стране во втором квартале 2020 года попросту замер [9].

Что касается рынка ИЖК, то его функционирование также отражало негативные тренды в условиях пандемии, что может быть наглядно проиллюстрировано на примере изменения ключевых показателей функционирования рынка ИЖК в апреле 2020 года в сравнении с аналогичным месяцем предыдущего года, см. Рисунок 1.

Такая ситуация кардинально откладывает и усложняет решение жилищной проблемы, что и активизировало внимание со стороны государства.

Среди мер, направленных на развитие рынка ИЖК в условиях пандемии:

- с 17 апреля сроком по 01.11.2020 г., в соответствии с Постановлением Правительства Российской Федерации от 23.04.2020 № 566 реализуется льготная программа ИЖК с конечной ставкой не более 6,5\%, с компенсацией дополнительных затрат банкам. Максимальная сумма кредита 3 млн. рублей (в Москве, Санкт-Петербурге, Московской и Ленинградской областях - 8 млн. рублей);

- 23 июня 2020 г. в телевизионном обращении к россиянам, Президент России Владимир Путин предложил распространить льготную ипотеку в 6,5\% на покупку нового жилья стоимостью до 6 млн. руб.

Кроме того, положительное влияние на рынок ИЖК должно оказать неуклонное снижение ключевой ставки Банка России, значение которой с 22 июня 2020 г. установлено на рекордно низком для нашей стране уровне $4,5 \%$.

Восстановление рынка ИЖК наблюдается уже по данным статистики за май месяц, хотя драйвером здесь выступало начало реализации льготной государственной ипотечной программы в соответствии с апрельскими решениями.

Субсидирование ставки по ИЖК со стороны государства будет иметь эффект ровно на протяжении того времени, пока будут действовать соответствующие программы, и лишь в отношении круга лиц, которые этими программами воспользуются. Снижение стоимости денежных ресурсов Банка России, при этом, окажет долгосрочный положительный эффект на процентные ставки. Впрочем, большими бенефициарами будут выступать крупнейшие федеральные банки, имеющие доступ к прямым заимствованиям у регулятора. Для региональных банков, как правило, работающих на основе базовой лицензии Банка России, условия улучшатся в меньшей степени. Некоторые сомнения вызывает возможный эффект, который окажут мероприятия на снижение ставки ИЖК через конкурентный механизм; по всей видимости, резервы внутри банковской оптимизации, позволявшие в прошлые годы отдельным банкам снижать ставки по собственным программам без субсидирования государством процентной ставки, уже исчерпаны. Растущий на фоне кардинальных мер правительства гэп между рыночными и субсидируемыми ставками, не может быть ликвидирован на основе одного лишь стремления банков сохранять конкурентоспособность собственных ипотечных программ: снижение ставок едва ли будет больше снижения ключевой ставки, а с учетом растущих рисков, их вклад также повлияет на незначительные масштабы снижения ставок по рыночным программам ИЖК.

На сегодня государство решило немало оперативных задач через новый виток вмешательства в рынок ИЖК: было стимулировано восстановление рынка ИЖК, пусть даже искусственным путем, и вместе с ним, стимулирует- 
ся и потребительская активность, и восстановление банковской деятельности, и некоторое оживление на рынках жилой недвижимости. Однако, при сохранении тенденций и реализуемых мер, уже в самом ближайшем времени потребуется либо принять болезненное решение об отмене субсидирования ставок, либо расширять его на весь рынок ИЖК, полностью заменив банковские программы ИЖК государственными. Кредитные организации, по сути, останутся лишь посредниками по выдаче ипотечных кредитов. Рынок ипотечного кредитования, в таком формате, будет практически полностью ориентирован на государственное финансирование, и традиционные программы ипотеки без участия государства просто будут закрыты, что едва ли рассматривается как цель государственной политики.

\section{Выво $и$ и рекомендации}

Государство, тем самым, остается основным инициативным участником рынка ипотечного кредитования, от политической воли и интересов которого в немалой степени зависит общее состояние и перспективы развития ипотечного рынка. Следствием пандемии может выступить усиление государственного участия на рынке ИЖК, и сохранение монополии крупнейших банков.

Несмотря на конъюнктурную пользу, данная ситуация едва ли видится положительной в долгосрочном контексте:

- государство общепризнанно не является эффективным операционным менеджером, и не должно подменять институты рыночной экономики, например, кредитные организации;

- коммерческие банки, которые и в прежних условиях не имели значительных стимулов развивать ипотечное кредитование, при длительном разрыве в стоимости ресурсов, направляемых на ипотечное кредитование в общем случае и по субсидированным программам, могут утратить окончательно интерес к собственным программам, для обеспечения которых необходимо обеспечивать жесткое управление собственными ресурсами;

- круг бенефициаров государственной политики будет ограничен участвующими банками и теми гражданами, которые подпали под участие в программах;

- бюджетно-финансовые ресурсы государства не безграничны, возможности их расходования на стимулирование ипотечного рынка существенно лимитированы.

В результате, государство и общество неизбежно предстают перед дилеммой о том, как при помощи льготной ипотеки, введенной в контексте противодействия негативному влиянию пандемии COVID-19, не только решить частные про- блемы текущего, бесспорно, беспрецедентно сложного периода, но и обеспечить стимулы для устойчивого сбалансированного развития ипотечного жилищного кредитования.

В контексте сказанного, представляется вновь обратить внимание субъектов государственной политики на ту роль, которую в системе ИЖК играют коммерческие банки. Никакое активное участие государства в ипотечном процессе их подменить не в состоянии.

Сильная банковская система с участием специализированных ипотечных банков и с глубоким проникновением доступных ипотечных продуктов в регионы,- залог эффективности применения инструментов ИЖК для целей решения жилищной проблемы в современной России. Банки с базовой лицензией могут более успешно реализовывать программы ИЖК совместно с крупными банками. Последние могут брать на себя систематические обязательства по рефинансированию ИЖК, выданных банками с базовой лицензией, либо, реализуя повышенную социальную ответственность, конструировать совместные ипотечные программы, реализуемые в партнерстве с региональными банками с базовой лицензией. Дополнительные обязательства, принимаемые в рамках таких программ, поспособствуют снижению аппетита банков к рискам в ипотечной сфере, тем самым, положительно влияя на стоимостной параметр доступности ИЖК.

Среди других перспективных решений также могут быть названы некоторые меры по снижению банковских рисков и их стоимости в стоимости ипотечных кредитов, - смягчение государственных требований по начислению обязательных резервов по данной категории кредитов, трансформация базы данных кредитных историй в универсальный цифровой инструмент сбора, агрегации и анализа данных о комплексной платежеспособности заемщиков - граждан, с последующим принятием решений о выдаче кредитов с применением самообучающихся интеллектуальных систем.

Наконец, следует заново обратиться к вопросу о развитии рынка ипотечных ценных бумаг, применять инструментарий активного привлечения инвесторов в сферу вторичного обращения производных ценных бумаг,- именно в этой сфере целесообразно и исключительно важно, чтобы государство взяло руководящую инициативу на себя.

Реализуя соответствующие меры, следует давать себе отчет в том, что пандемия коронавируса,- - не только вызов, но и время возможностей для принятия ответственных решений по поводу структурных и системных преобразований в проблемных сферах, тем более, что именно в непростых условиях общество консолидировано и будет готово принять радикальные реформаторские меры. 


\section{ЛИТЕРАТУРА}

1. Богданов А. С. Институт кредитования в современном российском обществе: понятие, принципы и механизмы правового обеспечения //Вестник Юго-Западного государственного университета Серия история и право.- 2017.-Т. 15.—C. 102-105.

2. Толстых И. А. Принципы реализации ипотечного жилищного кредитования для повышения уровня и качества жизни населения //Инновационная экономика: перспективы развития и совершенствования.— 2016.— № . 1 (11). — С. 263-269.

3. Ghaleno M.R., Ezazi M. E. Identification of Effective Factors on Admitting the Secondary Market of Housing Mortgage for Housing Finance in Tehran Province // International Business Management. - 2016. - Vol. 10. - N. 16. - P. 3396-3402.

4. Merzlyakova A.Y., Kotlyachkova N. V. The Program of State Support of the Mortgage Lending Market as a Way Out of the Crisis //The International Science and Technology Conference" FarEastCon".- - Springer, Cham, 2018. - P. 99-105.

5. Святловский, В. В. Жилищный и квартирный вопрос в России: избранные статьи / В. В. Святловский.— М.: РОССПЭН, 2012.— 373, [2] с.

6. Россияне о качестве ЖКХ [Электронный ресурс]. Режим доступа: https://wciom.ru/index.php?id=236\&uid=9786, свободный. Дата 0бращения: 02.07 .2020$.

7. Косарева Н.Б., Полиди Т. Д. Доступность жилья в России и за рубежом //Вопросы экономики. — 2019. — № . 7.— - С. 29-31.

8. Анализ развития конкурентной среды на рынке ипотечного кредитования в июне 2020 г.: Аналитические материалы А0 «ДОМ.РФ» от 26 июня 2020 г. [Электронный ресурс]. Режим доступа: https://дом.pф/upload/iblock/f12/f12c9d06d1a05442e0bf9321ab1ce03a.pdf, свободный. Дата 0бращения: 02.07.2020.

9. «Рынок недвижимости полностью замер»: что будет с ценами на жилье//PБК. - 26.05.2020 [Электронный ресурс]. Peжим доступа: https://realty.rbc.ru/ news/5ессс4869а794703755са8е4, свободный. Дата обращения: 02.07.2020.

10. Итоги развития рынка ипотеки в апреле и мае 2020 года [Электронный ресурс]. Режим доступа: https://дом.pф/upload/iblock/b38/b38fc5e0c378484b8123 db10da744937.pdf, свободный. Дата обращения: 02.07.2020.

( ) Метревели Елизавета Георгиевна ( metrevelieg@yandex.ru ), Наточеева Наталья Николаевна.

Журнал «Современная наука: актуальные проблемы теории и практики»

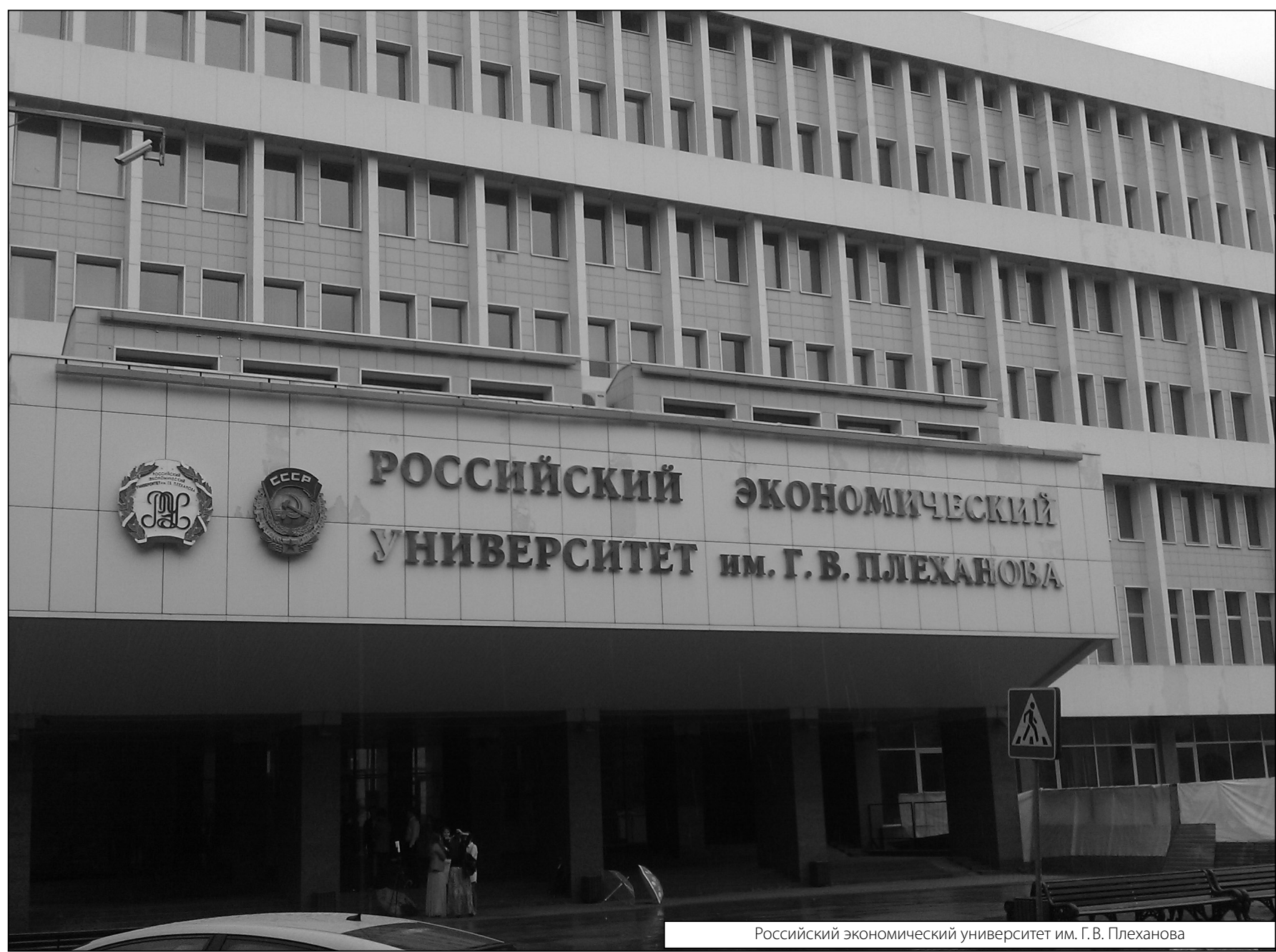

